when sixteen communications were made and discussed. Nany are of general interest :- Voeikoff (St. Petersburg), the influence of water on the heat balance of the earth; Vernadski (St. Petersburg), gaseous interchange in the earth's crusi; Tochidlovski (Odessa), formation of the elements of fog ; Aganin (Odessa), new hypothesis of formation of thunderstorms; Dubecki, actinometric observations at the glacier of Bercl. In the joint meeting of this section and the Section of Physics four communications were presented. Prince Golitzin (St. Petersburg) gave an account of the actual state of seismology, and Rosenthal (Warsaw) spoke about the determination of the depth of the origin of earthquakes.

(5) Considerable interest was taken in the Section of Astrophysics; in three meetings eleven papers were read. Of these we mention :-Amaftunski (Vilna), theory of sunspots as resulting from the activity of prominences; Tikhoff (Pulkovo), on the scintillation of stars; light-filters applied to the study of physical properties of Mars and Saturn; optical properties of solar prominences; Donich (St. Petersburg), astrophysical investigation of complete solar eclipses; Neuimin, advances of selenium-astrophotometry; Arzikhovski (Novocherkassk), spectra of planets obtained by Slipher, and the spectrum of chlorophyll.

Many papers were also read at meetings of the sections of metallography and technical electrochemistry; aërodynamics; biochemistry and biophysics; agricultural chemistry; hygiene; and didactics, the last-named being devoted to methods of teaching physics and chemistry in colleges (gymnasiums), and kindred matters.

The exhibitions of physical and chemical apparatus were very successful, and many foreign firms took part in them (viz. A. Hilger, C. Zeiss, Heraeus, Füss, and others). In spite of the cold (on some days a temperature of $-25^{\circ}$ was registered), more than sixty excursions were made to different works and institutions of St. Petersburg and its environs. Almost all museums were open to the members of the congress, and the provincial members made the most of this occasion to acquaint themselves with the capital. After the end of our congress many members took part in the Congresses of Applied Geology and Mathematics, which were inaugurated in St. Petersburg on January 9

\section{RELATION BETWEEN HEIGHT AND LENGTH OF THE WAVES FINALLY PRODUCED AT SEA BY WINDS OF ANY GIVEN SPEED.'}

BSERVATIONS made by the author, and those cf Scoresby, Paris, Abercromby, and others, show that when the waves in a storm are fully developed they travel with the same speed as the wind which produces them. If there be any excess velocity of wind, such as might be supposed necessary to prevent the waves from flattening out through the effect of friction, it is a quantity so small that it falls within the errors of observation. Similarly for the breakers which reach our coasts after storms in the Atlantic, the author has recorded periods which show a deep-water velocity equal to the maximum recorded velocity of the wind during the same spell of weather, the latter being in one case Beaufort's force $\mathrm{rI}$, or 64 statute miles per hour, and in another case Beaufort's 12, or 77 statute miles per hour. He has never recorded breakers with a speed equal, or nearly equal, to the speed which the wind momentarily attains in gusts, the speed of the waves not exceeding the average speed of the wind. The observations indicate that if there be any waves which travel faster than the wind, they do not attain sufficient amplitude to form breakers.

Since the highest waves finally produced travel with the same speed as the wind, their period and length can be at once precisely calculated for any given speed of wind. The recorded heights of fully developed waves for all weathers, from "strong breeze" to "strong gale," 25 to 44 statute miles per hour, are proportional to the speed of the wind, the multiplier being 0.7. Thus the height of the waves finally produced in a strong breeze, such as that of the trade winds, is $25 \times 0.7=17.5$ feet, and in the ordinary

1 Summary of a Cantor lecture delivered before the Royal Society of Arts on January 22 by Dr. Vaughan Cornish.

NO. 2206, VOL. 88] "strong gale" of the North Atlantic $44 \times 0.7=30 \cdot 8$ feet. The length of the waves being precisely calculable from the speed of the wind their flatness can be calculated by dividing by the empiric number for height. The ratio of iength to height is thus proportional to the velocity of the wind, the multiplier being $0 \cdot 6$.

\begin{tabular}{|c|c|c|c|c|c|c|c|}
\hline Description of wi & & 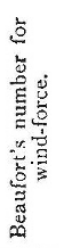 & 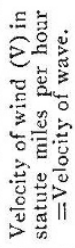 & 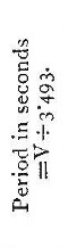 & 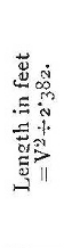 & 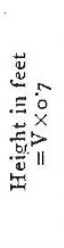 & 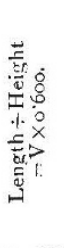 \\
\hline Strong breeze & $\ldots$ & 6 & 25 & $7 \cdot 2$ & 262 & $17 \cdot 5$ & $15^{\circ} \mathrm{O}$ \\
\hline Moderate gale & $\ldots$ & 7 & 31 & $8 \cdot 9$ & 404 & $2 \mathrm{r} \cdot 7$ & 18.6 \\
\hline Fresh gale & $\ldots$ & 8 & 37 & $10 \cdot 6$ & 575 & $25^{\circ} 9$ & $22 \cdot 2$ \\
\hline Strong gale & $\ldots$ & 9 & 44 & 12.6 & 813 & $30 \cdot 8$ & $26 \cdot 4$ \\
\hline Whole gale & $\ldots$ & 10 & 53 & $15 \cdot 2$ & I 180 & $37 \cdot 1$ & $3^{1 \cdot 8}$ \\
\hline Storm $\quad \ldots$ & $\ldots$ & I I & 64 & $18 \cdot 3$ & 1720 & $44 \cdot 8$ & $3^{8} \cdot 4$ \\
\hline Hurricane & $\ldots$ & 12 & 77 & $222^{\circ} \mathrm{O}$ & 2489 & & \\
\hline
\end{tabular}

The author recently obtained measurements of large waves in unusually favourable circumstances, the ship, P. and O. ss. Egypt, being hove-to for nine hours in the Bay of Biscay during the storm of December $2 \mathrm{I}$, I9I. The following velocities of wind are the means of two sets of estimates of the Beaufort's number. At 4 a.m., velocity of wind, 48.5 statute miles per hour; 8 a.m., 46.5 ; noon, 35.5 . The velocities of the waves were :-8 a.m., 47 statute miles per hour; Io a.m., 43.5 ; noon, 39.5 . At Io a.m. the prevailing height of wave was 3 I feet, very ferv being lower. There was no "swell," i.e. no waves longer and flatter than these, neither werc there any noticeable short waves. This remarkable "sea" was the effect of a very strong wind upon a heavy swell already running in precisely the same direction. The speed of this swell, as observed in the positions occupied by the ship on the preceding day, was 40 statute miles per hour. Its height was usually about is $_{5}$ feet, individual crests rising occasionally to a little more than 20 feet.

\section{QUANTITATIVE STUDIES IN EPIDEMIOLOGY.}

THE publication of a paper on this subject by Sir Ronald Ross in a recent issue of NATURE ${ }^{1}$ prompts me to present a note which I had been holding over for a longer article, and have also incorporated in a paper read before the Washington Philosophical Society. ${ }^{2}$ At the same time, I wish to offer a solution for a certain system of differential equations obtained by Sir Ronald Ross-a solution which presents certain points of interest.

\section{I.}

We may set ourselves the problem of investigating the relation between the number of the infected population (the focus of infection), the total population, the "infectiousness" of the disease, and its mean duration. We shall here restrict our considerations to the case of a disease such as pulmonary phthisis, which is more or less constantly present (i.e. not epidemic in its occurrence). Brief reflection shows that we can apply to this case a mathematical treatment precisely analogous to that of the growth of a population; for we may think of the diseased portion of the population as a separate aggregate, into which new individuals are recruited by fresh infections, just as new individuals enter an ordinary population by procreation. On the other hand, members are continually eliminated from the aggregate, first by deaths, secondly by recoveries. On the basis of these considerations, formulæ can without difficulty be established between the

1 October 5, Igri, p. 466

2 November lished in the Journal of the Washington Academy of Sciences, January and February, 1912. 
factors enumerated above. Such general formulæ, however, involve certain functions which are unknown, and the determination of which by statistical methods would at best present great difficulties. The matter assumes a somewhat more favourable aspect if we are satisfied with the discussion of the simple special case of a stationary population in which the disease also is supposed to have reached equilibrium.

We may then proceed as follows :-

Let $\mathrm{N}$ be the total number of the population, and $\mathrm{N}_{1}$ the number afficted with the disease.

Let $\mathrm{S}=\mathrm{N} s$ be the total number of deaths per unit of time, and let $S_{1}=N_{1} s_{1}$ be the number of deaths per unit of time due to the disease considered.

Let $N_{1} \sigma_{1}=N_{1} \frac{s_{1}}{\tau}$ be the total number of individuals eliminated from the aggregate of diseased persons per unit of time from all causes, including deaths by the disease under consideration, by other diseases, and also recoveries.

When a stationary condition is reached, $\sigma_{1}$ must be equal to the reciprocal of the mean duration $\mathrm{L}$ of the disease.

In this case we have, then,

$$
\mathrm{N}_{1} s_{1}=\mathrm{N}_{1} \frac{\tau}{\mathrm{L}}
$$

Furthermore, if $\gamma$ is a factor indicating that fraction of the total deaths which is due to the disease considered, then

$$
\mathrm{N}_{1} s_{1}=\mathrm{N}_{1} \frac{\tau}{\mathrm{L}}=\gamma \mathrm{N} s \ldots . . .
$$

Hence

$$
\mathrm{N}_{1}=\frac{\gamma \mathrm{L} s}{\tau} \ldots \ldots . . . .
$$

or, solving for $\mathrm{L}$,

$$
\mathrm{L}=\frac{\mathrm{N}_{1}}{\mathrm{~N}} \frac{\tau}{\gamma s} .
$$

By the way of a numerical example, I will substitute in the formula thus obtained some data gathered from the statistics of New York City. The supposition of a stationary population and equilibrium condition of the disease is quite unwarranted here, but in the absence of more suitable material, and in view of the great uncertainty of the figures obtainable, we shall have to rest content with this very crude illustration.

In 1909 the population of New York numbered about 4.5 millions. The total number of consumptives at the time has been estimated at about 45,000 . Hence $\frac{N_{1}}{N}=0$.0r. The death-rate per head per annum from all causes was 0.016 ; that from tuberculosis alone, 0.002. Hence

$$
\begin{aligned}
s & =0.016 \\
\gamma s & =0.002 \\
\gamma & =0.125 .
\end{aligned}
$$

The coefficient $\tau$ represents a measure of the "deadliness" of the disease-i.e. it expresses what fraction of the persons once struck with the disease ultimately die therefrom. It is difficult to obtain any kind of estimate of the value of $\tau$. We will assume that $\tau=0.8$.

We then have by (4)

$$
\mathrm{L}=\frac{0.01 \times 0.8}{0.002}=4 \text {. }
$$

In view of the crudity of the data on which it is based, this calculation must be regarded purely as an illustration of the principles involved, and not in any sense as an attempt to determine L, although the endeavour has been made to preserve at least the right order of magnitude in the example given.

\section{II.}

In dealing with metaxenous diseases, Sir Ronald Ross obtains the equations

$$
\begin{aligned}
& \frac{d z}{d t}=k^{\prime} z^{\prime}(p-z)+q z \ldots \ldots \\
& \frac{d z^{\prime}}{d t}=k z\left(p^{\prime}-z^{\prime}\right)+q^{\prime} z^{\prime} \ldots \ldots . . .
\end{aligned}
$$

He points out that

$$
\frac{a z}{d t}=\frac{d z^{\prime}}{d t}=0
$$

when

$$
\begin{aligned}
& z=\frac{k k^{\prime} p p^{\prime}-q q^{\prime}}{k k^{\prime} p^{\prime}-k q}=\mathrm{A} \ldots \ldots \\
& z^{\prime}=\frac{k k^{\prime} p p^{\prime}-q q^{\prime}}{k k^{\prime} p-k^{\prime} q^{\prime}}=\mathbf{A}^{\prime} \ldots \ldots . . . .
\end{aligned}
$$

Let us introduce new variables

$$
\begin{aligned}
& \mathrm{Z}=z-\mathrm{A} \\
& \mathrm{Z}^{\prime}=z^{\prime}-\mathrm{A}^{\prime}
\end{aligned}
$$

Equations (5), (6) then appear in the form

$$
\begin{aligned}
& \frac{d Z}{d t}=a Z+b Z^{\prime}+c Z Z^{\prime} \ldots \ldots \\
& \frac{a Z^{\prime}}{d t}=a^{\prime} Z+b^{\prime} Z^{\prime}+c^{\prime} Z Z^{\prime} \ldots \ldots
\end{aligned}
$$

where the coefficients $a, a^{\prime}, b, b^{\prime}, c, c^{\prime}$ are functions of $k, k^{\prime}, p, p^{\prime}, q, q^{\prime}$. If these latter are constant, the solution of (II), (I2) can immediately be written down in series form, namely,

$\mathrm{Z}=\mathrm{A}_{1} e^{-h t}+\mathrm{B}_{1} e^{-1: t}+\mathrm{A}_{2} e^{-2 h t}+\mathrm{B}_{2} e^{-h+\mathrm{H}) t}+\mathrm{C}_{2} e^{-2 \mathrm{H} t}$

$$
+\mathrm{A}_{3} e^{-3 h t}+\mathrm{B}_{3} e^{-(2 h+\mathrm{H}) t}+\mathrm{C}_{3} e^{-(h+2 \mathrm{H}) t}+\mathrm{D}_{3} e^{-3 \mathrm{H} t}+\ldots . \text {. (I3) }
$$

and a similar series for $Z^{\prime}$. The constants of these series can be evaluated by substituting the solution in the original equations and equating the coefficients of homologous terms of the right-hand and left-hand member. In particular, we thus obtain

$$
\begin{aligned}
& h=-\frac{1}{2}\left\{\left(a+b^{\prime}\right)+\sqrt{\left(a-b^{\prime}\right)^{2}+4} a^{\prime} b_{i}^{\prime} . . .\right. \text {. (14) } \\
& \left.H=-\frac{1}{2}\left\{\left(a+b^{\prime}\right)-\sqrt{\left(a-b^{\prime}\right)^{2}+4 a^{\prime} b}\right\} . . \text { (I } 5\right)
\end{aligned}
$$

This result throws an interesting light on the character of the path by which the final "static" condition is reached; the process is oscillatory so soon as

$$
\left(a-b^{\prime}\right)^{2}+4 a^{\prime} b<0
$$

The solution (13) is then preferably written in trigonometric form,

$\mathrm{Z}=e^{-m t}\left(\mathrm{P}_{1} \cos n t+\mathrm{Q}_{1} \sin n t\right)+e^{-2 m t}\left(\mathrm{P}_{2} \cos 2 n t+\mathrm{Q}_{2} \sin 2 n t+\mathrm{R}_{2}\right)+$

$e^{-3 m t}\left(\mathrm{P}_{3} \cos 3 n t+\mathrm{Q}_{3} \sin 3 n t+\mathrm{R}_{3} \cos n t+\mathrm{S}_{3} \sin n t\right)+\ldots$ (I 6$)$

with a similar series for $Z^{\prime}$. It will be observed that for large values of $t$ both $Z$ and $Z^{\prime}$ follow the law of damped harmonic oscillation, with a common period, and a phase difference depending on the value of the constants $a, a^{\prime}, b, b^{\prime}$.

In conclusion it may be remarked that Sir Ronald Ross's equations (5) and (6) can still be solved by the method here set forth if the coefficients $k, k^{\prime}, p, p^{\prime}, q, q^{\prime}$ of those equations are not constants, but functions of $z$ and $z^{\prime}$. The right-hand members of equations (II) and (I2) are then obtained as Taylor's series for two variables, and thus extend to an infinite number of terms. This does not in any way affect the form of the solutions (13), (16), which remain valid also in these circumstances.

ALFRED J. LOTKA.

\section{NATIONAL SYSTEMS OF EDUCATION. ${ }^{1}$}

THE International Council of Women has issued a special pamphlet entitled "National Systems of Education," which ought to prove useful to educationists and to the large body of voluntary workers who interest themselves in educational progress. The pamphlet comprises short accounts of the leading features of education in the various countries or States represented within the International Council of Women-United States, Canada, Germany, Sweden, Great Britain and Ireland, Denmark, Netherlands, New South Wales, Victoria and Queensland in Australia, Tasmania, New Zealand, France, Switzerland, Austria, Hungary, Norway, Belgium, Greece, Russia, Finland, Italy, Servia, and Bulgaria.

These accounts have been contributed by the members of

1 First Report of the Education Committee of the International Council of Women, compiled by Mrs. Ogilvie Gordon, Convener. Pp. 94. (Aberdeen, Rosemount Press.) Price $6 d$.

NO. 2206, VOL. 887 